\title{
An Analysis of the Current Situation of the Chinese Clothing Craze in the Context of the Rejuvenation of Chinese Culture
}

\author{
Pan Xiaodie ${ }^{1, a^{*}}$, Zhang Haixia ${ }^{2, b}$, Zhu Yongfei ${ }^{3, c}$ \\ ${ }^{1}$ Nanfang College of Sun Yat-sen University, Guangzhou, Guangdong, 510000, China \\ ${ }^{2}$ South China Normal University, Guangzhou, Guangdong, 510000, China \\ *Corresponding author. Email:562849196@qq.com, haixiavvzhang@163.com
}

\begin{abstract}
The origin of Hanfu is very early, but the development of Hanfu has gone through a long process from rebirth to symbolism. It witnessed the prosperity and decline from the Yellow Emperor period to the late Ming and early Qing Dynasty, along with the common growth of the Chinese nation. From the Yellow Emperor's accession to the throne to the end of Ming Dynasty and the beginning of Qing Dynasty, in the main residential areas of the Han nationality, the Chinese etiquette culture was the center, which affected the whole Han culture circle. Nowadays, we are looking back to Chinese culture and reshaping the "Hanfu fever" of Chinese civilization, so that people can gradually understand what is the deep dress and the right lapel. Hanfu has become an indispensable part of Chinese civilization which has been passed down for thousands of years.

Keywords: Hanfu, Chinese culture, cultural rejuvenation, national spirit
\end{abstract}

\section{THE BACKGROUND OF THE REVIVAL OF HANFU}

For thousands of years, the Chinese nation has been the nickname of the Han nation. The word "Hanfu" was first seen in the biography of the western regions of the Han Dynasty: "after the number of pilgrims, the clothing system of the Han Dynasty will be happy.". According to Liaoshi yiweizhi Yufu, "after Emperor Taizong entered Jin Dynasty, the emperor and the officials of Southern Han Dynasty used Hanfu; the Empress Dowager and the officials of northern Khitan used Guofu, whose Hanfu was the legacy of five Jin Dynasties." The minority regime began to clearly use "Hanfu" to refer to the Han costume. "Hanfu", as a noun, is the name given by ethnic minorities to the costumes of the Han nationality in the Central Plains in the process of ethnic communication. In recent years, some young people advocate to wear the traditional costume of the Han nationality, forming the "Hanfu craze" and "Hanfu movement", and "Hanfu" as the name of the traditional costume of the Han nationality began to be widely used. In the ten years of Zuozhuan's reign, it is said: "China has great etiquette, so it is called Summer; it has the beauty of clothing and regulations, so it is called Hua.". Its name "Hua" is derived from her magnificent Chinese dress, Hanfu. Nowadays, there are such a group of young people who launched the Hanfu movement in the network camp in order to find their own clothes and awaken the sleeping national culture. With it, the trend of "Hanfu fever" is driven. "Hanfu fever" is far more than simply finding clothes, it hides a group of Chinese people's childlike heart to revive Chinese traditional culture.

\section{THE RISE OF "HANFU FEVER"}

In 2001, when China successfully held the Asia Pacific Economic Cooperation summit in Shanghai, the delegates wore Tang suits and appeared. After that, Hanfu gradually returned to the public view. After that, Tang suit was well-known and was once regarded as China's national costume. However, many knowledgeable fans of Hanfu in China do not agree with this view. In fact, Tang costume is not the costume of Tang Dynasty, it can't live up to the letter. Nowadays, with the rapid growth of China's economy, the Chinese people began to take pride in the excellent traditional culture, and other national cultures in China began to return to the contemporary society, so the "Hanfu movement" came into being. "Hanfu movement" has become the beacon of "Hanfu fever", which is developing in full swing in the modern Chinese land. Hanfu once again appeared in the public field of vision in November 2003, when Wang Letian, a citizen of Zhengzhou, wore Hanfu in deep clothes for street display. Singapore's Lianhe Morning Post took the lead in reporting and reprinted by many media, which was regarded as the beginning of modern "Hanfu movement" by Hanfu fans. After that, "Hanfu fever" and "Hanfu movement" gradually rose, and Hanfu fans regarded it as a symbol of "Chinese cultural renaissance". During the two sessions in 2007, ye Hongming, a member of the CPPCC, proposed to define Hanfu as the national uniform, and Liu Minghua, a deputy to the National People's Congress, proposed to change the current western style academic dress to Hanfu style, which is the first time that Hanfu's topic has appeared in the two sessions. On the eve of the Beijing Olympic Games, in the 
discussion about the entrance dress of Chinese team members, the fans of Hanfu proposed to adopt Hanfu "deep dress", and the supporters and opponents had a heated discussion, so that the "Hanfu movement" formed a new climax. At the same time, the public's cognition and attitude towards Hanfu are still inconsistent. Most people regard Hanfu as "kimono" and "Hanfu". In 2004, eight young people wearing Hanfu were regarded as "Shouyi Shangjie" on Wangfujing Street in Beijing. Even if you know it's ancient Chinese clothing, you still feel incomprehensible and can't accept it in your daily life.So far, the activities of Hanfu fever have the following characteristics:

First, in terms of age, the fans are mainly the young people of the post-80s and post-90s. They are well-educated, have strong independent consciousness and personal opinions, and are easy to accept non mainstream culture. Most people are attracted by the intuitive beauty of Hanfu at first, and become conscious advocates of Hanfu after they understand Hanfu culture.

Second, in terms of activity mode, it mainly focuses on Internet forum and city Enthusiast Association: Baidu Hanfu bar, self-built website forum and QQ group are the most frequently used Internet Forum; the Enthusiast Association mainly develops its members and organizes activities centering on the city. Traditional media is also a way for fans to promote Hanfu. In recent years, the number of reports on Hanfu by newspapers and TV programs has increased year by year.

Third, the main content of the activity is to introduce and promote Hanfu, and advocate wearing Hanfu on festivals, sacrifices and other important occasions. Hanfu lovers also try to save the folk customs that are about to disappear and restore many festivals that have disappeared. For example, according to the traditional custom of offering sacrifices to $\mathrm{Qu}$ Yuan, shooting five poisons and tying five colored silk, the Dragon Boat Festival will be resumed, such as the ceremony of releasing vegetables, the ceremony of releasing libations, the festival of Shangsi, the ceremony of shooting, the ceremony of crowning, and the wedding ceremony of the joint prison. These activities are regarded as an important part of national cultural rejuvenation by Han costume lovers.

Fourth, the tendency of commercialization. Hanfu activities and other cultural organizations, such as folk Academy of Chinese studies, guqin and guzheng society, cooperate to organize activities for win-win. Hanfu craze also gave birth to Hanfu production, design, sales and other business activities.

\section{PROBLEMS UNDER THE "HANFU FEVER"}

The popularity of Hanfu began to rise in China. As a cultural symbol of ancient civilization, the disappearance and reappearance of Hanfu implies the discourse power and value orientation of clothing. The rise of Hanfu fever embodies the discovery of local national consciousness in the postcolonial context, and it is a kind of cultural conscious activity and a direct presentation of cultural pluralism in the postmodernist context. As a cultural symbol, Hanfu has been deeply embedded in the national memory for thousands of years. But as an old daily dress, wearing it in today's real life will undoubtedly make people feel strange. "Hanfu fever" still has some problems.

\section{1 "Hanfu fever" is "retro" or "Renaissance"}

At the beginning of the Hanfu movement, it was questioned and criticized by "retro". "These actions are only a return to the past in the form of cultural representation, cultural symbols or cultural carriers," said a member of the National Committee of the Chinese people's Political Consultative Conference These activities are more like a "show". In my opinion, it is not accurate to judge the "return to the ancients in form". In the eyes of Hanfu fans, this is not only a formal performance. They wear Hanfu, perform ancient rites, and celebrate traditional festivals. Through the interpretation of these forms, they find their own cultural identity, form cultural psychology, and achieve the identity of national culture. A performer who finds his own cultural orientation in the multi culture and recognizes it in the form of symbols is a renaissance in the cultural sense. The so-called form is a form with profound connotation, not a pure form, nor a "show" for "show". Hanfu lovers find a long lost sense of awe in the ancient worship, find the nourishment of culture for the dry soul in the interpretation of traditional festivals, and find the support of traditional values for the spirit. Most of the fans of Hanfu are the post-80s and the post-90s. Growing up in the context of multiple values, it is undoubtedly of rare positive significance to revive traditional culture in today's materialistic era. Since the ancient excellent ideology and culture can provide us with nutrition, as the symbol of the required culture, it is not impossible for modern people to use it. In this way, such a return to the ancients is not valueless, it is not a reversal of history.

\subsection{The validity of Hanfu as a cultural symbol}

At a press conference in 2006, Sun Jiazheng, then Minister of culture, said: "some young people are advocating wearing Hanfu, but I still don't know what kind of clothes can really represent China's clothes? This is probably the biggest puzzle we face. " This is a question about the validity of Hanfu as a cultural symbol. It should be noted that the popularity of Hanfu is not an isolated phenomenon in the trend of "cultural renaissance". In recent years, at the national two sessions, many representatives put forward the question of whether the national flower, the national tree, the national mountain and the traditional Chinese characters can be restored. Confucius, as a cultural symbol, has successfully promoted Chinese overseas, which reflects the recognition of national cultural symbols. In terms of clothing, both the new cheongsam and the new 
Tang suit have been loved by the public. Both of them combine the elements of traditional clothing with the modern style and shape better. They not only attach importance to the basic elements of traditional clothing language, but also give up the inappropriate places such as the indistinguishable point sleeves and the lack of three-dimensional sense. In fact, they have become symbols of Chinese culture. However, Han costume lovers are more in pursuit of the antiquity and purity of symbols. They believe that the new Tang costume and the new cheongsam are improved from the Manchu's mandarin jacket and the old cheongsam, and cannot be regarded as Han costume symbols. As a national costume of the Han nationality, Hanfu, which has lasted for thousands of years, is more ancient and pure. Intuitively, the long sleeved robe of Chinese clothing in China has lost its existing soil. However, when observing neighboring Japan and South Korea, its traditional clothing, as a symbol of national culture, shines brilliantly. On grand festivals and major occasions, suits, kimonos and Korean clothing coexist at the same time. In this way, Hanfu is not the reason why it does not continue to exist. It still needs time to prove whether Hanfu can become a cultural symbol recognized by modern people. In order to make the public agree with Hanfu, the experience of the combination of the new Tang suit and the new cheongsam is worth learning.

\subsection{Nationalism or narrow nationalism}

One of the goals of the Hanfu craze is to make Hanfu a "national costume". Yu Qiuyu said, "if Chinese people want to wear Hanfu, they will enter the concept of nationalism. Now that they have entered the concept, I want to ask: where do you put the 50 minority nationalities?" Obviously, "national costume" has already had the political meaning. In a unified multi-ethnic country, it needs to be considered carefully to define a certain kind of costume as national costume.

\section{REFLECTIONS ON THE "HANFU FEVER"}

The emergence of Hanfu craze has caused great trouble to the modern development of Hanfu. At the same time, it also gives people a way to think. The rise of the fashion craze of Han nationality stems from the loss and anxiety of Han nationality's cultural identity in the world communication. In the cultural collision between China and the West for more than 100 years, the western modern civilization has surpassed the Chinese traditional civilization with absolute superiority. China was forced to embark on the road of modernity and break away from tradition step by step. All levels of society are influenced by the West. As a national symbol and symbol, clothing has been completely changed with the Westernization of ideology and social political system. The society has chosen to accept Western clothing rather than restore the traditional Chinese clothing. After the reform and opening up, the common value system previously provided by social and political movements collapsed, and the impact of multiple values made people feel lost in their cultural identity. The enhancement of economic strength and the restoration of national self-confidence have also prompted people to re-examine their national cultural identity. What Chinese people should be like, what China should be like, has become a hot topic of this era. Corresponding to other post-colonial countries, China began to reflect on the value of its traditional culture and re identify with national symbols. The "Hanfu movement" of Hanfu lovers starts from the clothing as a cultural symbol to recognize and revive Chinese culture.

\section{CONCLUSION}

To sum up, a nation's clothing is an integral part of its culture, which is integrated with other cultural contents. For thousands of years, the traditional clothing of the Han nationality was interfered by external forces rather than died out normally. Fortunately, the culture did not die out. It is the cultural consciousness of costume cultural heritage that Han costume lovers reflect on the local cultural value and seek spiritual return to deduce the revival movement of Han costume. Whether Hanfu can be recognized as an effective cultural symbol of national identity is a problem in its integration with the civilization of the times. The external discourse of political power and cultural hegemony has caused tragedy to the traditional costume of the Han nationality. I hope this tragedy will not be repeated. Hanfu fever needs natural development space, but it also needs to avoid the tendency of extreme nationalism and Han chauvinism. With the development of the revival of Hanfu, the essence of rejuvenating traditional culture and carrying forward national spirit behind the revival of Hanfu has a positive role in promoting the development of national culture and strengthening national cohesion. We should treat this revival movement of national culture rationally and inherit the connotation of national traditional culture.

\section{REFERENCES}

[1] Liang xiaoxiao; Linyi University; To see through the return of national culture behind the "hanfu fever"; Northern Literature; No.05, 2017;

[2] Li Bei; Cultural thinking behind the "hanfu fever"; The Yellow River Civilization and Sustainable Development Research Center of Henan University; Journal of Tianzhong; No.04, 2015;

[3] Zhang Qiqi; Looking at the development of cultural confidence from the "Chinese clothing craze"; College of Marxism, Hunan University of Science and Technology; Comparative Study of Cultural Innovation; Issue 21, 2019 
[4] LIN Lin; The characteristics and inheritance and innovation of Han dynasty costumes; Tianjin Institute of Arts and Crafts; Art and Design2012 issue;

[5] Gong Huilin; Liu Wen; Hu Gaoyang; An analysis of the cultural connotation of Chinese clothing under the background of "hot Chinese clothing"; Jiaxing University; Shandong Textile Economy; 01 issue of 2020;

[6] Zheng Jijun; Clothing discourse and thinking about the Han clothing craze: School of Philosophy and Social Development, Huaqiao University; Journal of Qingdao Technical College; Issue 02 of 2012; 